\title{
ANALISIS SWOT PRODI DIII HUMAS FIS UNJ
}

\author{
Dini Safitri
}

\begin{abstract}
Prodi D3 Public Relations FIS UNJ standing since June 3, 2005, by Decree No.1846 / D / T2005. In the development of these courses has been developed into a favorite Prodi, but a number of studies need to be done to get accurate data that Prodi DIII FIS PR UNJ some of the authors are interested kelebihan.Untuk perform a SWOT analysis. The results showed that the $S$ or the strength of the study program is to produce qualified graduates, have a qualified lecturer, low cost, study programs of public universities have a good name. $W$ or weakness of the study program is accredited $\mathrm{C}$ and inadequate facilities. $\mathrm{O}$ or opportunities are expanding relations department of street vendors as graduates opportunities to work anyway. T or threat Prodi is a demand immediately improve lectures, use of introductory English, open S1, not to compete with PTN / PTS other more favorites.
\end{abstract}

Keywords: SWOT Analysis, Prodi DIII Public Relations UNJ

Abstrak

Prodi D3 Hubungan Masyarakat FIS UNJ berdiri sejak 3Juni 2005, berdasarkan SK No.1846/D/T2005. Dalam perkembangannya program studi ini telah berkembang menjadi prodi favorit, namun sejumlah penelitian perlu dilakukan untuk mendapatkan keakuratan data bahwa Prodi DIII Humas FIS UNJ memiliki sejumlah kelebihan.Untuk itu penulis tertarik melakukan analisis SWOT. Hasil penelitian menunjukan bahwa $S$ atau kekuatan prodi adalah menghasilkan lulusan berkualitas, memiliki dosen berkualitas,biaya murah, prodi dari universitas negeri yang memiliki nama baik. W atau kelemahan prodi adalah akreditasi $\mathrm{C}$ dan fasilitas yang kurang memadai. $\mathrm{O}$ atau peluang prodi adalah memperluas relasi PKL sebagai peluang lulusan untuk bekerja tetap. $T$ atau ancaman prodi adalah tuntutan segera memperbaiki fasilitas perkuliahan, penggunakan pengantar berbahasa Inggris, membuka program S1, agar tidak kalah bersaing dengan PTN/PTS lain yang lebih favorit.

Kata kunci: Analisis SWOT, Prodi DIII Humas UNJ

\section{Pendahuluan}

Prodi D3 Hubungan Masyarakat FIS UNJ berdiri sejak 3Juni 2005, berdasarkan SK No.1846/D/T2005. Dalam perkembangannya program studi ini telah berkembang menjadi prodi favorit. Indikator dari hal tersebut adalah bahwa 
jumlah peminat Prodi D3 Komunikasi UNJ sejak tahun 2004 sampai dengan 2012 memiliki kecenderungan meningkat setiap tahunnya. Selain jumlah peminat, lulusan dari Prodi DIII Hubungan Masyarakat FIS UNJ juga telah diserap oleh pasar kerja (data terlampir). Dari sekitar 134 lulusan prodi D3 Komunikasi UNJ diperoleh informasi bahwa sekitar 75\% nya telah bekerja dan sisanya meneruskan pendidikan ke jenjang S1.

Hal penting lainnya, Prodi DIII Hubungan Masyarakat FIS UNJ juga terus berusaha meningkatkan kualitas sumber daya manusia dengan tenaga pengajar yang berlatarbelakang keilmuan komunikasi. Demikian juga dengan peningkatan kualitas mahasiswa. Prodi D3 komunikasi UNJ memiliki mitra kerja dengan beberapa perusahaan.

Berikut ini beberapa instansi yang menjadi mitra kerja:

Tabel 1.1 Mitra Kerja Prodi DIII Hubungan Masyarakat FIS UNJ

\begin{tabular}{|c|c|c|}
\hline No. & Nama Instansi/ Perusahaan & Alamat \\
\hline 1. & $\begin{array}{llll}\text { Departemen } & \text { Tenaga } & \text { Kerja } & \text { dan } \\
\text { Transmigrasi } & & & \end{array}$ & Jl. Jend. Gatot Subroto Kav. 51 Jakarta \\
\hline 2. & Jawa Pos Group & Jl. Gunung Sahari Jakarta Pusat \\
\hline 3. & PT. Pertamina (Persero) & $\begin{array}{l}\text { Jl. Medan Merdeka Timur 1A Gedung } \\
\text { Perwira }\end{array}$ \\
\hline 4. & Biro Humas dan Protokol DKI & Jl. Medan Merdeka Selatan No. 8-9 \\
\hline 5. & \begin{tabular}{llr} 
Departemen & \multicolumn{2}{l}{ Komunikasi dan } \\
Informatika & (Badan Informasi \\
Publik) & &
\end{tabular} & $\begin{array}{l}\text { Jl. Medan Merdeka Barat No. } 9 \text { Jakarta } \\
\text { Pusat }\end{array}$ \\
\hline 6. & Trans 7 TV & Jl. Kapt. Tendean Mampang Prapatan \\
\hline 7. & Info Media Nusantara & Jl. Rs. Fatmawati 77-81 Jakarta \\
\hline 8. & Departemen Kehutanan RI & Jl. Gatot Subroto Lt.1 \\
\hline 9. & Hotel Bumiwiyata Depok & Depok \\
\hline 10. & Mahkamah Institusi & Jl. Medan Merdeka Barat \\
\hline 11. & PT. Pelabuhan Indonesia & Jl. Tanjung Priok Jakarta \\
\hline 12. & Perusahaan Listrik Negara & Gambir \\
\hline
\end{tabular}




\begin{tabular}{|l|l|l|}
\hline 13. & $\begin{array}{l}\text { Departemen Pariwisata dan } \\
\text { Kebudayaan }\end{array}$ & Jl. Merdeka Barat 17 Jakarta \\
\hline 14. & Ditjen Pos dan Telekomunikasi & Jl. Merdeka Barat 17 Jakarta \\
\hline 15. & Perum Perumnas & Jl. DI Panjaitan Kav 11 \\
\hline 16. & Walikotamadya Jakarta Timur & Cakung Jakarta Timur \\
\hline 17. & PT. Mustika Ratu & Jl. Gatot Subroto Jakarta Selatan \\
\hline 18. & Global Talent & Pamulang \\
\hline 19. & PT. ASDP Ferry & Jl. Jend. A. Yani Jakarta Pusat \\
\hline
\end{tabular}

Berdasarkan potensi dan peluang yang dimiliki tersebut, Penelitian ini dilakukan untuk mengembangkan SWOT Prodi DIII Hubungan Masyarakat FIS UNJ, khususnya dari pengamatan mahasiswa baru angkatan 2011. Hal ini penting untuk bahan evaluasi prodi agar menjadi dasar acuan untuk menyediakan sumber daya manusia yang lebih handal dan profesional dalam bidang ilmu komunikasi khususnya humas untuk dapat menduduki fungsi manajemen strategis organisasi di dalam pasar kerja. Baik pada organisasi komersial maupun non komersial. Berdasarkan latar belakang diatas, rumusan masalah dalam penelitian ini adalah: 'Bagaimana Analisis SWOT Prodi DIII Humas FIS UNJ ?'

\section{Metodologi Penelitian}

Jenis penelitian yang digunakan adalah penelitian kualitatif. Salah satu pendekatan yang digunakan dalam penelitian kualitatif adalah Analisis SWOT. Subjek penelitian adalah mahasiswa baru prodi DIII Humas FIS UNJ angkatan 2010. Subjek penelitian dipilih berdasarkan purposif sampling, informan ini juga telah merasakan fenomena dari permasalahan peneliti, serta bersedia untuk mengeksplorasi dan mengartikulasikan pengamalan mereka secara sadar.

Informan dalam penelitian ini dipilih penulis dengan kriteria: 1) Mahasiswa baru yang aktif mengikuti perkuliahan di semester satu dan dua, dilihat dari presensi perkuliahan di kelas, dan 2) Mahasiswa baru yang memiliki pembimbing akademik. Wawancara telah dilakukan dengan 39 mahasiswa baru prodi DIII Humas FIS UNJ yang representatif sebagai subjek penelitian, yang selanjutnya 
disebut sebagai informan. Teknik Pengumpulan Data menggunakan tiga teknik pengumpulan data yaitu metode wawancara mendalam (in-depth interview), observasi partisipatif (participant observation), dan analisis dokumen.

Wawancara atau interview adalah pengumpulan data dengan mengajukan pertanyan secara langsung kepada informan dan jawaban-jawabannya akan dicatat atau direkam dengan recorder. Wawancara mendalam (dalam Bungin, 2004:108-114) merupakan suatu cara mengumpulkan data atau informasi dengan cara langsung bertatap muka dengan informan, dengan maksud mendapatkan gambaran lengkap tentang topik yang diteliti. Wawancara mendalam dilakukan secara intensif dan berulang-ulang. Pada penelitian kualitatif, wawancara mendalam menjadi alat utama yang dikombinasikan dengan observasi partisipasi.

Teknik observasi partisipatif (dalam Alwasilah, 2002:154) dilakukan untuk menarik inferensi (kesimpulan) ihwal makna dan sudut pandang informan, kejadian, peristiwa, atau proses yang diamati. Lewat observasi ini peneliti akan melihat pemahaman yang tidak terucapkan (tacit understanding), bagaimana teori digunakan langsung (theory in use) dan sudut pandang informan yang mungkin tidak tercungkil lewat wawancara.

Peneliti melakukan pendekatan secara intensif untuk membangun rapport (dalam Alwalsilah, 2002:144), rapport adalah hubungan yang ditandai kesesuaian, kesepakatan, persetujuan, atau kedekatan antara peneliti dan yang diteliti. Membangun rapport adalah mekanisme untuk mengurangi jarak psikologis, mencairkan ketegangan, dan membangun kepercayaan informan terhadap peneliti sehingga informan mau mengungkapkan informasi yang diperlukan kepada peneliti dengan perasaan nyaman (tanpa rasa takut atau terpaksa).

Analisis dokumen dengan menelusuri dokumentasi berupa buku, majalah, koran, dan informasi dari internet yang berhubungan dengan penelitian. Analisis dokumen ini yaitu merupakan tehnik pengumpulan data yang tidak langsung ditujukan kepada subjek penelitian. Dokumen yang diteliti berbagai macam dan meneliti sumber serta referensi yang mendukung penelitian dalam bentuk literatur bahan kajian dan internet. 


\section{Hasil Penelitian}

Hasil penelitian ini menguraikan hasil Analisis SWOT yang terdiri dari empat faktor, yaitu:

1. Strengths (kekuatan): merupakan kondisi kekuatan yang terdapat dalam organisasi. Dalam penelitian ini organisasi yang dimaksud adalah Prodi Humas DIII UNJ.

2. Weakness (kelemahan): merupakan kondisi kelemahan yang terdapat dalam organisasi, yaitu kelemahan dalam Prodi Humas DIII UNJ.

3. Opportunities (peluang): merupakan kondisi peluang berkembang di masa datang yang terjadi. Kondisi yang terjadi merupakan peluang dari luar, misalnya kompetitor, kebijakan pemerintah, kondisi lingkungan sekitar.

4. Threats (ancaman): merupakan kondisi yang mengancam dari luar. Ancaman ini dapat mengganggu organisasi, yaitu menganggu Prodi Humas UNJ.

Berikut ini Analisis informan mengenai SWOT Prodi DIII Humas UNJ:

Tabel 4.1 Analisis SWOT

\begin{tabular}{|c|c|c|c|c|}
\hline Informan & $S$ & W & $\mathrm{O}$ & $\mathrm{T}$ \\
\hline 1. GI & $\begin{array}{l}\text { 1. Lulusan: terampil, } \\
\text { berkualitas, mampu } \\
\text { berbahasa asing. } \\
\text { 2. Dosen: ahli di } \\
\text { bidangnya, } \\
\text { berwawasan global }\end{array}$ & $\begin{array}{l}\text { Fasilitas } \\
\text { 1. Kelas: bangku } \\
\text { kurang layak pakai } \\
\text { 2. Kampus: tembok } \\
\text { kusam }\end{array}$ & $\begin{array}{l}\text { 1. Kesempatan } \\
\text { kerja luas } \\
\text { (pemerintah \& } \\
\text { swasta) } \\
\text { 2. Banyak } \\
\text { Pelatihan soft } \\
\text { skill dari Prodi } \\
\text { untuk } \\
\text { Mahasiswa }\end{array}$ & $\begin{array}{l}\text { Fasiltas } \\
\text { minim, } \\
\text { menurunkan } \\
\text { minat calon } \\
\text { mahasiswa }\end{array}$ \\
\hline 2. MUK & $\begin{array}{l}\text { 1. Lulusan: siap } \\
\text { kerja, dilatih } \\
\text { menjadi humas } \\
\text { profesional, mudah } \\
\text { melamar kerja } \\
\text { karena dari }\end{array}$ & $\begin{array}{l}\text { 1. Akreditasi C } \\
\text { 2. Fasilitas kurang } \\
\text { memadai }\end{array}$ & $\begin{array}{l}\text { 1. Lulusan } \\
\text { berpeluang besar } \\
\text { dalam } \\
\text { mendapatkan } \\
\text { pekerjaan karena } \\
\text { dari Universitas }\end{array}$ & $\begin{array}{l}\text { 1. Banyak PTS } \\
\text { membuka } \\
\text { DIII Humas } \\
\text { dengan } \\
\text { Pengantar } \\
\text { Bahasa }\end{array}$ \\
\hline
\end{tabular}




\begin{tabular}{|c|c|c|c|c|}
\hline & $\begin{array}{l}\text { Universitas Negeri } \\
\text { 2. Biaya kuliah } \\
\text { murah } \\
\text { 3. Dosen berkualitas } \\
\text { dan banyak } \\
\text { memberi pelatihan }\end{array}$ & & $\begin{array}{l}\text { Negeri } \\
\text { 2. Peluang } \\
\text { mendapatkan } \\
\text { beasiswa besar } \\
\text { 3. Peluang } \\
\text { membuka } \\
\text { tambahan kelas } \\
\text { (jika } \\
\text { mendapatkan } \\
\text { tambahan } \\
\text { ruangan) } \\
\text { 4. Peluang } \\
\text { akreditasi A, jika } \\
\text { fasilitas dibenahi } \\
\text { dan prestasi terus } \\
\text { dicapai }\end{array}$ & $\begin{array}{l}\text { Inggris } \\
\text { 2. Tidak } \\
\text { menggunakan } \\
\text { pengantar } \\
\text { Bahasa } \\
\text { Inggris } \\
\text { 3. Fasilitas } \\
\text { kurang } \\
\text { memadai } \\
\text { 4. Akreditasi } \\
\text { C }\end{array}$ \\
\hline 3. RAA & $\begin{array}{l}\text { 1. Lulusan siap } \\
\text { bekerja } \\
\text { 2. Universitas negeri }\end{array}$ & $\begin{array}{l}\text { 1. Fasilitas kurang } \\
\text { 2. Prodi hanya DIII }\end{array}$ & $\begin{array}{l}\text { Kelas PR dapat } \\
\text { membangun } \\
\text { gedung sendiri } \\
\text { dan dapat } \\
\text { menerapkan } \\
\text { sistem beli kelas } \\
\text { (sponsor) }\end{array}$ & $\begin{array}{l}\text { Tidak } \\
\text { menggunakan } \\
\text { pengantar } \\
\text { bahasa Inggris } \\
\text { seperti PTS }\end{array}$ \\
\hline 4. GS & $\begin{array}{l}\text { 1. Universitas negeri } \\
\text { 2. Lulusan siap kerja }\end{array}$ & $\begin{array}{l}\text { Fasilitas kurang } \\
\text { memadai }\end{array}$ & $\begin{array}{l}\text { Lulusan lebih } \\
\text { diutamakan } \\
\text { bekerja karena } \\
\text { dari Universitas } \\
\text { Negeri }\end{array}$ & $\begin{array}{l}\text { PTN/PTS } \\
\text { memiliki } \\
\text { fasilitas lebih } \\
\text { unggul }\end{array}$ \\
\hline 5. BNA & $\begin{array}{l}\text { 1. Universitas negeri } \\
\text { 2. Dosen berkualitas }\end{array}$ & $\begin{array}{l}\text { 1. Fasilitas kurang } \\
\text { memadai } \\
\text { 2. Prodi hanya DIII }\end{array}$ & $\begin{array}{l}\text { Prodi memiliki } \\
\text { link/jaringan/cha } \\
\text { nnel yang luas }\end{array}$ & Akreditasi C \\
\hline
\end{tabular}




\begin{tabular}{|c|c|c|c|c|}
\hline & & & $\begin{array}{l}\text { sehingga lulusan } \\
\text { mendapat } \\
\text { pekerjaan tetap } \\
\text { dan terjamin }\end{array}$ & \\
\hline 6. SA & $\begin{array}{l}\text { 1. Dosen berkualitas } \\
\text { (metode mengajar, } \\
\text { sesuai kompetensi) } \\
\text { 2. Satu-satunya } \\
\text { Universitas Negeri } \\
\text { di Jakarta yang ada } \\
\text { prodi Humas-nya }\end{array}$ & $\begin{array}{l}\text { 1. Akreditasi C } \\
\text { 2. Kriteria penilai } \\
\text { dosen ketat, banyak } \\
\text { mahasiswa } \\
\text { mengulang sehingga } \\
\text { lulus tidak tepat } \\
\text { waktu } \\
\text { 3. Fasilitas kurang } \\
\text { memadai }\end{array}$ & $\begin{array}{l}\text { 1. Prodi memilik } \\
\text { kerja sama pada } \\
\text { beberapa instansi } \\
\text { sehingga } \\
\text { memudahkan } \\
\text { mahasiswa } \\
\text { mencari kerja } \\
\text { 2. Perusahaan } \\
\text { lebih mencari } \\
\text { lulusan } \\
\text { Universitas } \\
\text { Negeri }\end{array}$ & $\begin{array}{l}\text { 1. Akreditasi } \\
\text { C } \\
\text { 2. Sulit } \\
\text { membuka } \\
\text { program S1 } \\
\text { karena } \\
\text { Akreditasi C }\end{array}$ \\
\hline 7. KISP & $\begin{array}{l}\text { 1. Universitas negeri } \\
\text { 2. Dosen berkualitas } \\
\text { dan berpengalaman } \\
\text { 3. Biaya kuliah } \\
\text { murah }\end{array}$ & $\begin{array}{l}\text { 1. Akreditasi C } \\
\text { 2. Fasilitas kurang } \\
\text { 3. Jadwal kuliah } \\
\text { terlalu pagi }\end{array}$ & $\begin{array}{l}\text { 1. Universitas } \\
\text { Negeri adalah } \\
\text { impian } \\
\text { 2. Tahapan } \\
\text { menjadi } \\
\text { mahasiswa prodi } \\
\text { melalui seleksi } \\
\text { ketat }\end{array}$ & $\begin{array}{l}\text { Fasilitas } \\
\text { kurang } \\
\text { sehingga } \\
\text { menganggu } \\
\text { kenyamanan } \\
\text { proses belajar }\end{array}$ \\
\hline 8. IA & $\begin{array}{l}\text { 1. Prodi yang saat } \\
\text { ini booming } \\
\text { 2. Dosen berkualitas } \\
\text { 3. Lulusan siap } \\
\text { kerja }\end{array}$ & $\begin{array}{l}\text { 1. Akreditasi C } \\
\text { 2. Beberapa dosen } \\
\text { jarang hadir } \\
\text { 3. Fasilitas kurang } \\
\text { terutama lab PR }\end{array}$ & $\begin{array}{l}\text { 1. Peluang dan } \\
\text { lapangan kerja } \\
\text { banyak } \\
\text { 2. Gaji tinggi }\end{array}$ & $\begin{array}{l}\text { 1. Banyak } \\
\text { PTN/PTS } \\
\text { membuka } \\
\text { prodi humas } \\
\text { 2. Fasilitas } \\
\text { PTN/PTS lain } \\
\text { lebih baik }\end{array}$ \\
\hline
\end{tabular}




\begin{tabular}{|c|c|c|c|c|}
\hline 9. MA & $\begin{array}{l}\text { 1. Dosen berkualitas } \\
\text { 2. Kurikulum baik } \\
\text { 3. Buku di } \\
\text { Perpustakaan } \\
\text { lengkap } \\
\text { 4.Banyak peminat } \\
\text { 5. Peluang kerja } \\
\text { lulusan banyak } \\
\text { 6. Prodi } \\
\text { bekerjasama dengan } \\
\text { beberapa } \\
\text { perusahaan } \\
\text { 7. Uang kuliah } \\
\text { murah }\end{array}$ & $\begin{array}{l}\text { 1. Fasilitas kurang } \\
\text { memadai } \\
\text { (kelas,toilet,kantin) } \\
\text { 2.Akreditasi C }\end{array}$ & $\begin{array}{l}\text { 1. Peluang dan } \\
\text { lapangan kerja } \\
\text { banyak }\end{array}$ & $\begin{array}{l}\text { 1. Akreditasi } \\
\text { C } \\
\text { 2. Tidak ada } \\
\text { program S1 di } \\
\text { Prodi }\end{array}$ \\
\hline 10. RDP & Uang kuliah murah & $\begin{array}{l}\text { 1. Akreditasi C } \\
\text { 2. Fasilitas kurang } \\
\text { 3. Prodi kurang } \\
\text { dikenal }\end{array}$ & $\begin{array}{l}\text { Sosialisasi Prodi } \\
\text { sebagai PTN } \\
\text { dengan uang } \\
\text { kuliah murah }\end{array}$ & $\begin{array}{l}\text { 1. Fasilitas } \\
\text { minim } \\
\text { membuat citra } \\
\text { negatif } \\
\text { 2. Banyak } \\
\text { pesaing } \\
\text { PTN/PTS lain }\end{array}$ \\
\hline 11. AYS & $\begin{array}{l}\text { 1.Kualitas lulusan } \\
\text { baik } \\
\text { 2.Dosen berkualitas }\end{array}$ & $\begin{array}{l}\text { 1. Fasilitas kurang } \\
\text { 2. Prodi hanya DIII }\end{array}$ & $\begin{array}{l}\text { 1. Daya tarik } \\
\text { Prodi tinggi bila } \\
\text { disosialisasikan } \\
\text { dengan baik } \\
\text { 2. Peluang kerja } \\
\text { lulusan banyak }\end{array}$ & $\begin{array}{l}\text { PTN/PTS lain } \\
\text { yang lebih } \\
\text { baik } \\
\text { fasilitasnya }\end{array}$ \\
\hline 12. NR & $\begin{array}{l}\text { 1. Peminat banyak } \\
\text { 2. Dosen berkualitas } \\
\text { 3. Lulusan } \\
\text { berkualitas dan siap }\end{array}$ & $\begin{array}{l}\text { 1. Fasilitas kurang } \\
\text { (kelas, lab PR) } \\
\text { 2. Metode Pengajaran } \\
\text { kurang }\end{array}$ & $\begin{array}{l}\text { 1. Peluang kerja } \\
\text { banyak } \\
\text { 2. Prodi memiliki } \\
\text { kerjasama }\end{array}$ & $\begin{array}{l}\text { 1. Belum } \\
\text { memiliki guru } \\
\text { besar } \\
\text { 2. PTN/PTS }\end{array}$ \\
\hline
\end{tabular}




\begin{tabular}{|c|c|c|c|c|}
\hline & kerja & $\begin{array}{l}\text { 3. Penggunaan } \\
\text { bahasa Inggris disaat } \\
\text { proses pembelajaran } \\
\text { kurang } \\
\text { 4. Banyak mahasiswa } \\
\text { tidak lulus pada } \\
\text { matakuliah tertentu } \\
\text { 5. Belum optimal } \\
\text { peran alumni } \\
\text { 6. Dosen sering tidak } \\
\text { masuk }\end{array}$ & magang & $\begin{array}{l}\text { lain yang } \\
\text { lebih unggul } \\
\text { 3. Hanya DIII }\end{array}$ \\
\hline 13. SNR & $\begin{array}{l}\text { 1. Izin berdiri sejak } \\
2005 \\
\text { 2. } 95 \% \text { Lulusan } \\
\text { bekerja } \\
\text { 3. Peminat banyak } \\
\text { 4. Terdapat PKL }\end{array}$ & $\begin{array}{l}\text { 1. Fasilitas kurang } \\
\text { 2. Penggunaan } \\
\text { Bahasa Inggris } \\
\text { kurang } \\
\text { 3. Banyak dosen } \\
\text { tidak masuk }\end{array}$ & $\begin{array}{l}\text { Lapangan kerja } \\
\text { banyak }\end{array}$ & $\begin{array}{l}\text { Persaingan } \\
\text { dengan } \\
\text { PTN/PTS }\end{array}$ \\
\hline 14. BS & $\begin{array}{l}\text { 1.Lulusan } \\
\text { berkualitas } \\
\text { 2.Dosen berkualitas }\end{array}$ & Fasilitas kurang & $\begin{array}{l}\text { 1.Lapangan kerja } \\
\text { banyak } \\
\text { 2.Sosialisasi prodi } \\
\text { agar dikenal luas }\end{array}$ & $\begin{array}{l}\text { Tidak } \\
\text { memiliki } \\
\text { program S1 }\end{array}$ \\
\hline 15. AS & $\begin{array}{l}\text { 1. Penggunan } \\
\text { teknologi informasi } \\
\text { baik } \\
\text { 2. Peningkatan } \\
\text { jumlah mahasiswa } \\
\text { PKL } \\
\text { 3. Permintaan } \\
\text { tenaga kerja oleh } \\
\text { alumni }\end{array}$ & $\begin{array}{l}\text { 1. Metode mengajar } \\
\text { belum efektif } \\
\text { 2. Fasilitas belum } \\
\text { terawat } \\
\text { 3. Kurang prestasi }\end{array}$ & $\begin{array}{l}\text { 1. Banyak } \\
\text { beasiswa } \\
\text { 2. Lapangan } \\
\text { pekerjaan banyak }\end{array}$ & $\begin{array}{l}\text { 1. PTS yang } \\
\text { lebih } \\
\text { profesional } \\
\text { 2. Persaingan } \\
\text { ketat }\end{array}$ \\
\hline
\end{tabular}




\begin{tabular}{|c|c|c|c|c|}
\hline & $\begin{array}{l}\text { 4. Dosen mengajar } \\
16 x \text { pertemuan }\end{array}$ & & & \\
\hline 16. PH & $\begin{array}{l}\text { 1. Lulusan } \\
\text { berkualitas } \\
\text { 2. Prodi dikenal } \\
\text { berbagai instasi } \\
\text { pemerintah dan } \\
\text { swasta }\end{array}$ & $\begin{array}{l}\text { 1. Fasilitas kurang } \\
\text { 2. Akreditasi C }\end{array}$ & $\begin{array}{l}\text { 1. Banyak } \\
\text { peminat } \\
\text { 2. Dosen } \\
\text { berkualitas } \\
\text { 3. Biaya murah } \\
\text { 4. Prodi memiliki } \\
\text { relasi kerja }\end{array}$ & $\begin{array}{l}\text { Fasilitas tidak } \\
\text { ada perbaikan }\end{array}$ \\
\hline 17. MZB & $\begin{array}{l}\text { 1. Prodi dikenal } \\
\text { berbagai instasi } \\
\text { 2. Lulusan langsung } \\
\text { kerja } \\
\text { 3. Biaya kuliah } \\
\text { murah }\end{array}$ & $\begin{array}{l}\text { 1. Fasilitas kurang } \\
\text { 2. Akreditasi C }\end{array}$ & $\begin{array}{l}\text { 1. Peminat } \\
\text { banyak } \\
\text { 2. Biaya kuliah } \\
\text { murah } \\
\text { 3. Relasi PKL } \\
\text { banyak }\end{array}$ & $\begin{array}{l}\text { 1. Fasilitas } \\
\text { tidak layak } \\
\text { 2. Lulusan } \\
\text { banyak, } \\
\text { banyak } \\
\text { saingan }\end{array}$ \\
\hline 18. EL & $\begin{array}{l}\text { 1. Lulusan } \\
\text { berkualitas } \\
\text { 2. Banyak peminat } \\
\text { 3.Dosen masih } \\
\text { berusia muda } \\
\text { namun berkualitas } \\
\text { 4.Tingkat kehadiran } \\
\text { dosen dalam } \\
\text { perkuliahan baik } \\
\text { 5. Prodi } \\
\text { berkerjasama } \\
\text { dengan beberapa } \\
\text { instansi }\end{array}$ & $\begin{array}{l}\text { 1. Fasilitas terbatas } \\
\text { 2. Buku penunjang } \\
\text { pembelajaran yang } \\
\text { lengkap hanya di } \\
\text { perpustakaan pusat } \\
\text { 3. Kurangnya } \\
\text { keterlibatan } \\
\text { mahasiswa dalam } \\
\text { penelitian dosen } \\
\text { 4. Belum banyaknya } \\
\text { kelompok studi di } \\
\text { tingkat mahasiswa } \\
\text { 5. Distribusi asal } \\
\text { daerah mahasiswa } \\
\text { dari seluruh }\end{array}$ & $\begin{array}{l}\text { 1. Besarnya } \\
\text { potensi } \\
\text { mahasiswa sbg } \\
\text { SDM profesional } \\
\text { 2. Prodi } \\
\text { hubungan } \\
\text { masyarakat lebih } \\
\text { dikenal } \\
\text { 3. Peluang kerja } \\
\text { besar } \\
\text { 4. Tersedianya } \\
\text { bahan ajar yang } \\
\text { bisa diakses } \\
\text { secara luas }\end{array}$ & $\begin{array}{l}\text { 1. Stigma } \\
\text { humas = EO } \\
\text { 2. Gaji lulusan } \\
\text { humas rendah } \\
\text { 3. Belum } \\
\text { banyak profil } \\
\text { lulusan yang } \\
\text { sukses secara } \\
\text { materi } \\
\text { 4. Tuntutan } \\
\text { fasilitas } \\
\text { lengkap dan } \\
\text { representatif } \\
5 . \\
\text { Kemandirian }\end{array}$ \\
\hline
\end{tabular}




\begin{tabular}{|c|c|c|c|c|}
\hline & & $\begin{array}{l}\text { Indonesia belum } \\
\text { merata } \\
\text { 6. Masih perlu } \\
\text { ditingkatkannya } \\
\text { standar evaluasi } \\
\text { pembelajaran di } \\
\text { dalam kelas } \\
\text { 7. Akreditasi C } \\
\text { 8. Belum dibuka } \\
\text { program S1 }\end{array}$ & & $\begin{array}{l}\text { mahasiswa } \\
\text { untuk } \\
\text { mengatasi } \\
\text { kesempatan } \\
\text { kerja yang } \\
\text { kecil karena } \\
\text { banyak } \\
\text { pesaing }\end{array}$ \\
\hline 19. DES & $\begin{array}{l}\text { 1. Izin sejak } 2005 \\
\text { 2. Universitas negeri } \\
\text { 3. Uang kuliah } \\
\text { murah } \\
\text { 4. Lulusan } \\
\text { berkualitas } \\
\text { 5. Dosen kompeten } \\
\text { dan muda }\end{array}$ & $\begin{array}{l}\text { 1. Akreditasi C } \\
\text { 2. Fasilitas kurang } \\
\text { 3. Dosen jarang } \\
\text { masuk }\end{array}$ & $\begin{array}{l}\text { 1. Banyak } \\
\text { peluang kerja } \\
\text { 2. Lulusan } \\
\text { dibutuhkan }\end{array}$ & $\begin{array}{l}\text { Banyak } \\
\text { lulusan } \\
\text { humas dari } \\
\text { akreditasi B, } \\
\text { A }\end{array}$ \\
\hline 20. DA & Lulusan berkualitas & Fasilitas kurang & $\begin{array}{l}\text { Lulusan } \\
\text { dibutuhkan }\end{array}$ & $\begin{array}{l}\text { Tuntutan } \\
\text { profesional }\end{array}$ \\
\hline 21. AM & $\begin{array}{l}\text { 1. Citra positif prodi } \\
\text { humas UNJ } \\
\text { 2. Letak strategis di } \\
\text { tengah kota Jakarta } \\
\text { 3. Dosen berkualitas } \\
\text { 4.Lulusan } \\
\text { berkualitas }\end{array}$ & $\begin{array}{l}\text { 1. Fasilitas dan } \\
\text { bangunan kurang } \\
\text { baik } \\
\text { 2. Praktek kurang }\end{array}$ & $\begin{array}{l}\text { 1. Segera } \\
\text { membuka } \\
\text { program S1 } \\
\text { 2. Alumni } \\
\text { berkualitas }\end{array}$ & $\begin{array}{l}\text { Fasilitas } \\
\text { minim } \\
\text { menghambat } \\
\text { penggalian } \\
\text { potensi dan } \\
\text { proses belajar }\end{array}$ \\
\hline 22. RFI & $\begin{array}{l}\text { 1. Dosen berkualitas } \\
\text { 2. Biaya kuliah } \\
\text { murah } \\
\text { 3. Lulusan }\end{array}$ & Fasilitas kurang & $\begin{array}{l}\text { Lulusan UNJ } \\
\text { diakui }\end{array}$ & $\begin{array}{l}\text { PTN/PTS lain } \\
\text { yang favorit }\end{array}$ \\
\hline
\end{tabular}




\begin{tabular}{|c|c|c|c|c|}
\hline & berkualitas & & & \\
\hline 23. RSDP & Universitas Negeri & $\begin{array}{l}\text { 1. Fasilitas kurang } \\
\text { 2. Kurang event } \\
\text { keluar } \\
\text { 3. Kurang praktek }\end{array}$ & $\begin{array}{l}\text { Peminat banyak } \\
\text { karena satu- } \\
\text { satunya univertas } \\
\text { negeri di Jakarta }\end{array}$ & $\begin{array}{l}\text { Fasilitas } \\
\text { minim, ruang } \\
\text { kelas sedikit }\end{array}$ \\
\hline 24. SF & $\begin{array}{l}\text { Prodi dari satu- } \\
\text { satunya univertas } \\
\text { negeri di Jakarta }\end{array}$ & $\begin{array}{l}\text { 1. Akreditasi C } \\
\text { 2. Fasilitas minim }\end{array}$ & $\begin{array}{l}\text { Peminat banyak } \\
\text { dari hasil seleksi }\end{array}$ & $\begin{array}{l}\text { Fasilitas } \\
\text { minim } \\
\text { menganggu }\end{array}$ \\
\hline 25. PSI & Dosen berkualitas & Fasilitas kurang & $\begin{array}{l}\text { Peluang kerja } \\
\text { luas }\end{array}$ & $\begin{array}{l}\text { Prodi baru } \\
\text { yang harus } \\
\text { meningkatkan } \\
\text { kualitas }\end{array}$ \\
\hline 26. DDA & $\begin{array}{l}\text { 1. PTN terbaik di } \\
\text { Jakarta } \\
\text { 2. Lulusan siap kerja } \\
\text { 3. Beasiswa Prestasi }\end{array}$ & $\begin{array}{l}\text { 1. Fasilitas minim (lab } \\
\text { dan kelas) } \\
\text { 2. Akreditasi C }\end{array}$ & $\begin{array}{l}\text { 1. Bahan ajar } \\
\text { yang dapat di } \\
\text { akses } \\
\text { 2. Lapangan kerja } \\
\text { banyak } \\
\text { 3. Lulusan PTN } \\
\text { lebih diutamakan }\end{array}$ & $\begin{array}{l}\text { 1. Tuntutan } \\
\text { perbaikan } \\
\text { fasilitas } \\
\text { 2. Dosen } \\
\text { kurang total } \\
\text { 3. Image } \\
\text { negatif prodi } \\
\text { humas } \\
\text { 4. PTN/PTS } \\
\text { yang fasilitas } \\
\text { lebih baik }\end{array}$ \\
\hline 27. SAP & $\begin{array}{l}\text { 1. Lulusan diminati } \\
\text { 2. Perusahaan } \\
\text { terkenal } \\
\text { 3. Universitas negeri } \\
\text { Biaya kuliah murah }\end{array}$ & $\begin{array}{l}\text { 1. Akreditasi C } \\
\text { 2. Fasilitas minim } \\
\text { 3. Belum ada } \\
\text { program S1 }\end{array}$ & $\begin{array}{l}\text { Peluang kerja } \\
\text { banyak }\end{array}$ & $\begin{array}{l}\text { Public } \\
\text { Speaking PTS } \\
\text { lebih baik }\end{array}$ \\
\hline 28. AR & $\begin{array}{l}\text { 1. Dosen muda dan } \\
\text { berkualitas } \\
\text { 2. Lulusan }\end{array}$ & $\begin{array}{l}\text { 1. Penggunaan } \\
\text { Bahasa Inggris } \\
\text { kurang }\end{array}$ & $\begin{array}{l}\text { 1.Peminat yang } \\
\text { banyak } \\
\text { 2.Tuntutan PTN }\end{array}$ & $\begin{array}{l}\text { PTN/PTS } \\
\text { yang memiliki } \\
\text { metode }\end{array}$ \\
\hline
\end{tabular}




\begin{tabular}{|c|c|c|c|c|}
\hline & berkualitas & $\begin{array}{l}\text { 2. Peran alumni } \\
\text { kurang } \\
\text { 3. Fasilitas kurang } \\
\text { 4. Rasio dosen dan } \\
\text { mahasiswa belum } \\
\text { ideal }\end{array}$ & internasional & $\begin{array}{l}\text { pengajaran } \\
\text { yang variatif } \\
\text { dan memiliki } \\
\text { guru besar }\end{array}$ \\
\hline 29. MF & $\begin{array}{l}\text { 1. Satu-satunya } \\
\text { Universitas Negeri } \\
\text { di Jakarta } \\
\text { 2. Dosen berkualitas }\end{array}$ & $\begin{array}{l}\text { 1. Fasilitas minim } \\
\text { (kelas bangku, tong } \\
\text { sampah) } \\
\text { 2. Kebersihan kurang }\end{array}$ & $\begin{array}{l}\text { Lulusan } \\
\text { berkualitas }\end{array}$ & $\begin{array}{l}\text { 1. Fasilitas } \\
\text { kurang } \\
\text { 2. Akreditasi } \\
\text { C }\end{array}$ \\
\hline 30. IR & $\begin{array}{l}\text { 1. Dosen muda dan } \\
\text { berkualitas dengan } \\
\text { tingkat kehadiran } \\
\text { baik } \\
\text { 2. Peminat banyak } \\
\text { 3. Universitas negeri }\end{array}$ & $\begin{array}{l}\text { 1. Akreditasi C } \\
\text { 2. Fasilitas kurang } \\
\text { 3. Minat organisasi } \\
\text { mahasiswa rendah } \\
\text { 4. Pengunaan bahasa } \\
\text { Inggris kurang }\end{array}$ & $\begin{array}{l}\text { 1. Lapangan kerja } \\
\text { banyak } \\
\text { 2. PKL sebagai } \\
\text { gerbang } \\
\text { lapangan kerja }\end{array}$ & $\begin{array}{l}\text { PTN/PTS } \\
\text { sejenis yang } \\
\text { lebih dulu } \\
\text { dengan dosen } \\
\text { berkualitas }\end{array}$ \\
\hline 31. RTS & $\begin{array}{l}\text { 1.Dosen } \\
\text { berpengalaman } \\
\text { 2.Prodi bekerjasama } \\
\text { dengan banyak } \\
\text { lembaga } \\
\text { 3. Fasilitas cukup }\end{array}$ & $\begin{array}{l}\text { 1. Fasilitas cukup tapi } \\
\text { kurang terawat } \\
\text { 2. Prodi kurang } \\
\text { dikenal luas } \\
\text { 3. Dosen muda } \\
\text { sedikit }\end{array}$ & $\begin{array}{l}\text { 1. Peluang kerja } \\
\text { banyak } \\
\text { 2. Banyak intansi } \\
\text { meminta lulusan } \\
\text { berkeja }\end{array}$ & $\begin{array}{l}\text { 1. PTN/PTS } \\
\text { lain yang } \\
\text { lebih lulusan } \\
\text { lebih } \\
\text { berkualitas } \\
\text { dan sarana } \\
\text { lengkap } \\
\text { 2. Hanya } \\
\text { program DIII }\end{array}$ \\
\hline 32. DD & $\begin{array}{l}\text { 1. Lulusan siap kerja } \\
\text { 2. Banyak peminat }\end{array}$ & $\begin{array}{l}\text { 1. Fasilitas minim } \\
\text { 2. Ada dosen yang } \\
\text { tidak menjelaskan } \\
\text { materi }\end{array}$ & $\begin{array}{l}\text { 1. Peluang kerja } \\
\text { banyak } \\
\text { 2. Waktu studi } \\
\text { lebih singkat } \\
\text { sehingga siap } \\
\text { kerja }\end{array}$ & $\begin{array}{l}\text { 1. Banyak } \\
\text { mahasiswa } \\
\text { mengundurka } \\
\text { n diri karena } \\
\text { waktu yang } \\
\text { tidak efektif }\end{array}$ \\
\hline
\end{tabular}




\begin{tabular}{|c|c|c|c|c|}
\hline & & & & $\begin{array}{l}\text { dan tuntutan } \\
\text { dosen yang } \\
\text { mengajar } \\
\text { seperti militer } \\
\text { 2. Fasilitas } \\
\text { kurang }\end{array}$ \\
\hline 33. M & $\begin{array}{l}\text { 1. Peminat banyak } \\
\text { 2. Dosen kompeten } \\
\text { 3. Lulusan siap kerja } \\
\text { dan mudah } \\
\text { mendapatkan } \\
\text { pekerjaan }\end{array}$ & $\begin{array}{l}\text { 1. Persaingan ketat } \\
\text { dengan PTN/PTS } \\
\text { 2. Fasilitas kurang } \\
\text { 3. Akreditasi C } \\
\text { 4. Penggunaan } \\
\text { bahasa asing kurang }\end{array}$ & $\begin{array}{l}\text { 1. Gaji tinggi } \\
\text { 2. Lapangan kerja } \\
\text { banyak }\end{array}$ & $\begin{array}{l}\text { 1. PTN/PTS } \\
\text { mempunyai } \\
\text { program S1 } \\
\text { 2.Susah lulus }\end{array}$ \\
\hline 34. SC & $\begin{array}{l}\text { 1. Universitas negeri } \\
\text { 2. Dosen kompeten } \\
\text { 3. Lulusan } \\
\text { berkualitas }\end{array}$ & $\begin{array}{l}\text { 1. Fasilitas kurang } \\
\text { 2. Akreditasi C }\end{array}$ & $\begin{array}{l}\text { 1. Peluang kerja } \\
\text { banyak } \\
\text { 2. Prodi memiliki } \\
\text { nama baik }\end{array}$ & $\begin{array}{l}\text { Tuntutan } \\
\text { memperbaiki } \\
\text { Akreditasi C }\end{array}$ \\
\hline 35. AR & $\begin{array}{l}\text { 1. Fasilitas memadai } \\
\text { 2. Dosen berkualitas } \\
\text { 3. Kurikulum sesuai } \\
\text { kompetensi } \\
\text { 4.Biaya kuliah } \\
\text { murah }\end{array}$ & $\begin{array}{l}\text { 1. Akreditasi C } \\
\text { 2. Belum banyak } \\
\text { peminat } \\
\text { 3. Belum ada S1 }\end{array}$ & $\begin{array}{l}\text { Waktu studi lebih } \\
\text { singkat namun } \\
\text { padat }\end{array}$ & $\begin{array}{l}\text { Tuntutan } \\
\text { memperbaiki } \\
\text { Akreditasi C }\end{array}$ \\
\hline 36. TP & $\begin{array}{l}\text { 1. Universitas negeri } \\
\text { 2. Lulusan siap kerja }\end{array}$ & $\begin{array}{l}\text { 1. Akreditasi C } \\
\text { 2. Sarana minin } \\
\text { untuk praktek }\end{array}$ & $\begin{array}{l}\text { 1. Lulusan } \\
\text { berdaya tarik } \\
\text { karena dari } \\
\text { universitas negeri } \\
\text { 2. Biaya kuliah } \\
\text { murah }\end{array}$ & $\begin{array}{l}\text { PTN/PTS lain } \\
\text { memiliki } \\
\text { program S1 } \\
\text { dan pengantar } \\
\text { bahasa Inggris }\end{array}$ \\
\hline 37. PRU & $\begin{array}{l}\text { 1. Universitas negeri } \\
\text { 2. Lulusan } \\
\text { berkualitas }\end{array}$ & $\begin{array}{l}\text { 1. Fasilitas minim dan } \\
\text { cat gedung kusam } \\
\text { 2. Siakad lambat }\end{array}$ & $\begin{array}{l}\text { 1. Peluang kerja } \\
\text { lebih besar dari } \\
\text { lulusan swasta }\end{array}$ & $\begin{array}{l}\text { 1. Akreditasi } \\
\text { C } \\
\text { 2. Belum ada }\end{array}$ \\
\hline
\end{tabular}




\begin{tabular}{|c|c|c|c|c|}
\hline & $\begin{array}{l}\text { 3. Prodi } \\
\text { bekerjasama dengan } \\
\text { berbagai instansi } \\
\text { 4. Kurikulum sesuai } \\
\text { kompetensi }\end{array}$ & $\begin{array}{l}\text { mempersulit } \\
\text { pengisian KRS } \\
\text { 3. Kurang buku } \\
\text { humas di } \\
\text { perpustakaan } \\
\text { 4. Prodi kurang } \\
\text { dikenal peminat }\end{array}$ & $\begin{array}{l}\text { 2. Prodi memiliki } \\
\text { kerja sama } \\
\text { dengan berbagai } \\
\text { instansi }\end{array}$ & S1 \\
\hline 38. NA & Lulusan berkualitas & $\begin{array}{l}\text { 1. Fasilitas minim } \\
\text { termasuk buku } \\
\text { 2. Akreditasi C }\end{array}$ & $\begin{array}{l}\text { Kesempatan kerja } \\
\text { luas }\end{array}$ & $\begin{array}{l}\text { PTN/PTS } \\
\text { yang } \\
\text { berbahasa } \\
\text { Inggris }\end{array}$ \\
\hline 39. DS & $\begin{array}{l}\text { 1. Lulusan banyak } \\
\text { dicari dan siap kerja } \\
\text { 2. Dosen berjiwa } \\
\text { muda, inovatif dan } \\
\text { kompeten } \\
\text { 3. Kurikulum sesuai } \\
\text { kompetensi }\end{array}$ & $\begin{array}{l}\text { 1. Fasilitas minim dan } \\
\text { kurang bersih } \\
\text { terutama kelas } \\
\text { 2. Angka kehadiran } \\
\text { dan kesadaran } \\
\text { mahasiswa kurang } \\
\text { 3. Akreditasi C }\end{array}$ & $\begin{array}{l}\text { Kesempatan kerja } \\
\text { luas } \\
\text { Bahan ajar luas }\end{array}$ & $\begin{array}{l}\text { 1. Persaingan } \\
\text { antar Lulusan } \\
\text { ketas } \\
\text { 2. Masih ada } \\
\text { anggapan } \\
\text { humas tidak } \\
\text { penting }\end{array}$ \\
\hline
\end{tabular}

Berdasarkan tabel SWOT diatas kita dapat mengerucutkan hal pokok yang menjadi SWOT Prodi DIII Humas UNJ yaitu:

S : Lulusan dan dosen berkualias, univesitas negeri, biaya kuliah murah

W : Fasilitas minim, Akreditasi C

O : Lapangan pekerjaan banyak

T : PTN/PTS yang lebih unggul dalam fasilitas, menggunakan pengantar bahasa Inggris, dan membuka program S1

Selain SWOT diatas informan juga memberikan sejumlah strategi untuk memperbaiki citra prodi DIII humas UNJ. Adapun strateginya:

1. Memperbaiki fasilitas serta penunjang belajar dengan yang lebih modern, terutama kelas 
2. Membudayakan penggunaan bahasa Inggris dan bahasa asing lainnya untuk menunjang kemampuan mahasiswa/i

3. Memperbanyak jumlah instansi pemerintah atau swasta untuk kerjasama magang program studi DIII humas UNJ

4. Membuat program S1 untuk melanjutkan DIII Humas di UNJ

5. Memperbaiki akreditasi prodi

6. Memperbaiki citra DIII humas yang dibilang sulit untuk lulus ketika TAKI, agar lulusan dapat menyelesaikan program studi tepat waktu sekaligus meningkatkan kualitas akademik

7. Memperbanyak perkuliahan umum dan pelatihan dengan mengundang PR Prosesional

8. Menambah dosen yang kompeten

9. Meningkatkan kualitas dan kompetensi akademik dosen dalam hal metode pengajaran dan pendidikan karakter dengan cara Pengembangan program pendidikan dan pengajaran, Pengembangan kompetensi dosen dan sarana penelitian

10. Memperbanyak promosi lewat media dan online agar Prodi Humas UNJ lebih dikenal orang

11. Memperbanyak PKL

12. Peningkatan intensitas bimbingan dosen kepada mahasiswa

13. Mengevaluasi program secara berkala dengan lebih mengutamakan kualitas dan prestasi berdasarkan skala prioritas, terutama meningkatkan prestasi mahasiswa prodi D3 UNJ baik dalam bidang akademik maupun non akademik

14. Mengadakan Studi banding dengan PTN/PTS lain

15. Menaikkan uang bayaran agar fasilitas dalam prodi untuk mahasiswa dan dosen memadai

16. Peningkatan kualitas layanan perpustakaan

17. Peningkatan kualitas pembinaan kegiatan kemahasiswaan dengan pengaktualisasian minat, bakat dan penalaran mahasiswa

18. Penyediaan dana yang menjamin upaya peningkatan mutu internal serta akreditasi secara terus menerus 
19. Memperketat mahasiswa pada peraturan-peraturan agar menjadi insan berkualitas

20. Mengadakan pertukaran mahasiswa

21. Memperbanyak beasiswa

22. Meningkatkan kedisiplinann dosen dan mahasiswa seperti kehadiran

23. Memperketat seleksi masuk calon mahasiswa agar lulusan lebih berkualitas

24. Sistem belajar mengikuti sistem belajar di Eropa

\section{Kesimpulan}

Analisis SWOT adalah suatu cara menganalisis faktor internal dan eksternal menjadi langkah strategi dalam pengoptimalan usaha yang telah menguntungkan. Dalam analisis faktor internal dan eksternal, akan ditentukan aspek yang menjadi kekuatan (Strengths), kelemahan (Weakness), kesempatan (Oppurtunities), dan yang menjadi ancaman (Threats) sebuah organisasi. Dengan begitu akan dapat ditentukan berbagai kemungkinan alternatif strategi yang dapat dijalankan (Freddy Rangkuli, 2005:19).

Hasil penelitian menyimpulkan, bahwa informan menyadari bahwa Kekuataan (S) dari Prodi Humas DIII UNJ adalah lulusan dan dosen berkualitas, prodi humas DIII UNJ memiliki nama besar sebagai universitas negeri dan satusatunya di Jakarta, serta biaya kuliah yang murah. Kelemahan (W) yang dimiliki prodi Humas DIII UNJ adalah fasilitas yang minim terutama fasilitas didalam kelas dan laboratorium PR yang menyebabkan suasana belajar tidak kondusif, serta akreditasi prodi yang bernilai C. Kesempatan (O) yang dimiliki prodi Humas UNJ adalah relasi prodi yang luas dengan berbagai intansi pemerintah dan swasta, menyebabkan lulusan mudah mendapatkan pekerjaan setelah lulus kuliah, selain itu prodi Humas DIII UNJ cukup memiliki banyak peminat, namun karena relatif baru berdiri, dan kurang sosialisasi, kurang dirasakan keberadaannya oleh masyarakat. Ditambah lagi, prodi humas DIII UNJ belum memiliki program lainnya, seperti program S1. Ancaman (T) untuk prodi humas UNJ yang berasal dari dalam adalah tuntutan perbaikan fasilitas, sedangkan ancaman dari luar adalah banyak PTN/PTS 
yang lebih unggul dalam fasilitas, menggunakan penggantar bahasa Inggris dan membuka program S1.

\section{Daftar Pustaka}

\section{Buku}

Bungin, Burhan. 2004. Metodologi Penelitian Kualitatif: Aktualisasi Metodologis ke Arah Ragam Varian Kontemporer. Jakarta: PT RajaGrafindo Persada.

Evans, James R., and Lindsay, William M..2005. The Management and Control of

Quality, Thomson, South Western : Australia.

Notoatmodjo, Soekidjo. 2003. Pendidikan dan Perilaku Kesehatan. Jakarta : PT Rineka Cipta.

Rangkuti, Freddy. 1997. Analisis SWOT Teknik Membedah Kasus Bisnis.Jakarta:Gramedia Pustaka Utama

Sam M. Chan - Tuti T. Sam. 2012. Analisis SWOT Teknik Membedah Kasus Bisnis. Jakarta: Rajawali Press.

Schuler.1986. Empowerment and the Law. USA: New Weave

Veneklasen, Lisa dan Valerie Miller. 2002. A New Wave of Power, People and

Politics. The Action Guide for Advocacy and Citizen Participation. USA: World Neighbours

\section{Kamus}

Pusat Bahasa Departemen Pendidikan Nasional. 2002. Kamus Besar Bahasa Indonesia. Jakarta : Balai Pustaka.

UU

.Undang-undang Republik Indonesia Nomor 20 Tahun 2003 Tentang Sistem Pendidikan Nasional.

\section{Online}

www.justassociates.org/ActionGuide.htm 
www.geocities,com/frans_98/uu/uu_20_03.htm. Diakses 10 Feb 2014 www. Humanikaconsulting.com

www.marketingteacher.com/Lessons/lessom_swot.htm

www.mindtools.com/swot.html

www.tutor2u.net/business/strategy/SWOT_analysis.htm 